\title{
DA CONVENÇÃO N 169 DA OIT À RESSIGNIFICAÇÃO DOS DIREITOS HUMANOS INDÍGENAS NAS CONSTITUIÇÕES LATINO AMERICANAS.
}

\author{
Adson Kepler Monteiro Maia ${ }^{1}$ \\ Saulo De Medeiros Torres ${ }^{2}$
}

Resumo: Este artigo analisa a evolução da Convenção $\mathrm{n}^{\mathrm{a}} 169$ da OIT, em comparação com a Convenção $\mathrm{n}^{\circ} 107$, dentro da temática de direitos humanos dos povos indígenas. Após apontar 0 contexto da globalização como elemento intensificador dos conflitos interculturais entre indígenas e o Estado, grupos econômicos e indivíduos, este artigo propõe, com base na teoria de Boaventura Santos, a utilização da hermenêutica diatópica, no âmbito da interpretação das normas jurídicas, com o fim de reduzir a complexidade de nossa realidade social multicultural e encontrar soluções através do diálogo entre normas internas e internacionais e do uso do controle de convencionalidade.

Palavras-chave: OIT; Convenção 169; Conflitos interculturais; Povos Indígenas; Direitos Humanos.

\section{OF THE ILO CONVENTION NO. 169 TO THE RESSIGNIFICATION OF INDIGENOUS HUMAN RIGHTS IN THE LATIN AMERICAN CONSTITUTIONS.}

\begin{abstract}
This article analyzes the evolution of ILO Convention 169, compared to Convention No. 107, within the human rights of indigenous peoples. After pointing out the context of globalization as an intensifying element of the intercultural conflicts between indigenous peoples and the State, economic groups and individuals, this article proposes, based on the theory of Boaventura Santos, the use of diatopic hermeneutics, within the scope of the interpretation of legal norms, with the purpose of reducing the complexity of our multicultural social reality and finding solutions through dialogue between internal and international norms and the use of conventionality control.
\end{abstract}

Keywords: ILO; Convention 169; Intercultural conflicts; Indigenous people; Human Rights.

\footnotetext{
${ }^{1}$ Delegado de Polícia Civil junto à Secretaria de Estado da Segurança Pública do Rio Grande do Norte. Possui Bacharelado em Direito (1995), Especialização em Ética (2004) e Especialização em Direito Internacional Público (2015), sempre pela Universidade Federal do Rio Grande do Norte. Tem interesse na área de Direito Constitucional, Direito Penal Internacional, Sistema Internacional de Proteção aos Direitos Humanos, Cooperação Jurídica Internacional em Matéria Penal, Criminalidade Transnacional, Direitos Fundamentais, Hermenêutica Constitucional e Ética.

${ }^{2}$ Possui Graduação em Direito pela Universidade Federal do Rio Grande do Norte (UFRN). Especialista em Direito Constitucional e Tributário pela Universidade Potiguar (UnP). Ex Professor Substituto na UFRN. Ex Conciliador (JFRN). Ex Professor Temporário na Universidade do Estado do Rio Grande do Norte. Mestrando em Direito pela UFRN.
} 


\section{INTRODUÇÃO}

Desde que o Frei dominicano Bartolomé de Las Casas conseguiu convencer boaparte da Igreja e autoridades constituídas de que os índios teriam alma, o reconhecimento de direitos para os povos originários das Américas foi lento até o final do século XX, principalmente no âmbito do direito internacional dos direitos humanos. Todavia, parece que essa realidade mudou a partir de novas concepções que fizeram surgir a Convenção $\mathrm{n}^{\mathrm{a}} 169$ da OIT e a revolução jurídica e social que ela representou no âmbito dos direitos humanos dos povos indígenas.

Este artigo analisa a evolução significativa da Convenção n ${ }^{a} 169$ da OIT, em contraste com a Convenção anterior da OIT para o mesmo tema, e os recentes dispositivos constitucionais na América Latina que trazem uma transformação significante dos direitos humanos de princípios meramente morais para princípios ecológicos na percepção de autores conceituados, apesar de muito recente e fragmentado o fenômeno.

Também se propõe uma reflexão sobre as constantes restrições aos direitos dos indígenas e a desigualdade de tratamento entre os povos originários conforme maior ou menor colaboração com os interesses externos a comunidade.

Sobre os conflitos interculturais ampliados pela globalização este artigo propõe, com base na teoria de Boaventura Santos, a utilização da hermenêutica diatópica, com o fim de reduzir a complexidade de nossa realidade multicultural de sociedade e encontrar soluções sempre respaldadas, internamente aos Estados, nos direitos fundamentais e, externamente no Direito Internacional, nos tratados de direitos humanos.

Como proteção internacional aos direitos dos povos originários surgiu a Convenção n ${ }^{0}$ 169 da OIT, porém, mais do que a proteção do direito internacional, as Constituições dos países latino-americanos têm incorporado, em consonância com a parcial abertura ao relativismo da

referida Convenção, princípios culturais de seus povos num processo intercultural de juridificação constitucional de valores tribais, estendendo-os em sua concretização a toda sociedade, respeitando-se sua pluralidade multicultural, como valores universaisinterculturais.

As violações de direitos humanos individuais e coletivos de povos indígenas não são uma realidade exclusiva do Brasil nem mesmo de países subdesenvolvidos e, dessa forma, necessitam de esforços a nível mundial para se obter o fim dessas violações.

Os conflitos de terras, os conflitos socioculturais e a exploração do trabalho de indígenas, assim como todas as restrições e violações a seus direitos humanos são questões de 
interesse das grandes organizações internacionais, como bem demonstram as duas convenções da OIT que trataram do tema e a declaração de direitos dos povos indígenas da ONU. Assim, pode-se inferir que essas violações não são, exclusivamente, uma questão de Segurança Pública ou de Segurança Nacional.

O estudo dos direitos humanos indígenas tem crescido em importância, já ocorrendo julgamento de casos na Corte Interamericana de Direitos Humanos, inclusive envolvendo o Brasil, no julgamento envolvendo os direitos indígenas do povo Xucuru, realizado no Tribunal Interamericano em 21 de março de 2017 (AGÊNCIA BRASIL, 2017).

A importância suscitada acima se percebe de vários fatores, mas destacamos a ampliação da globalização e o chamado transconstitucionalismo. A globalização aqui entendida como um fenômeno de extraordinária amplitude de interações transnacionais econômicas, sociais, culturais e políticas, um fenômeno que pode ocorrer tanto de forma hegemônica como contra-hegemônica (SANTOS, 2005).

Acrescenta-se o transconstitucionalismo entendido aqui como um fator que se constitui no entrelaçamento de ordens jurídicas diversas, tanto estatais como transnacionais, internacionais e supranacionais, em torno dos mesmos problemas de natureza constitucional (NEVES, 2009). No caso da questão dos Xucurus contra o Brasil várias questões estão sob a jurisdição nacional, porém a própria demora na resposta gera uma sobreposição de jurisdições visto que uma das alegações de violação é a própria demora na decisão judicial.

Os fatores acima ampliam a possibilidade de conflitos interculturais em vários níveis, mas não se pretende neste artigo se aprofundar na descrição e análise desses fatores. Nosso objetivo é mostrar as violações passadas e atuais contra direitos humanos de povos indígenas, seu contexto atual no âmbito do Direito Internacional dos Direitos Humanos, e a ressignificação desses direitos em favor das causas desses povos.

Já existem demonstrações práticas no Brasil desses conflitos na demarcação de terras indígenas, nas relações jurídicas dos crescentes números de descendentes de indígenas que almejam resgatar suas raízes em conflito com o Estado ou interesses privados. Na reinvindicação de comunidades ciganas (também protegidas pela Convenção nº 169 da OIT), comunidades quilombolas e outros exemplos de comunidades culturalmente isoladas.

Destaca-se como emblemática a decisão judicial que mais abarcou esses conflitos interculturais na questão indígena: aquela do caso da demarcação das terras indígenas conhecidas como "Raposa Serra do Sol” em Roraima (objeto de decisão do Supremo Tribunal 
Federal $)^{3}$.

Sobre a construção do direito através da decisão judicial, a Suprema Corte detém poder constituinte material e detendo-o, remanesce sempre o constituinte originário, titular de decisão política básica. Na “interpretação” da norma o magistrado aloja-se dentro da Constituição; na “construção”, quando o é no direito púbico, vai mais além, perpetuando o constituinte primeiro, cujo ato é substancialmente político. Só judicial, às vezes; outras judicial e política; tal é a função jurisdicional do supremo órgão da justiça, subjacente a qual está a nação (VILLANOVA, 1979).

Para evitar que a decisão judicial e política, como explicada acima, tenha um contorno não extraído da Ciência Jurídica em integração com outros campos científicos, necessário se faz compreender a interculturalidade de forma interdisciplinar, ou mesmo, transdisciplinar.

A Administração Pública e seus agentes públicos, quando diante de conflitos interculturais, como os que serão abordados a seguir, não podem criar normas na mesma dimensão acima (decisão judicial), restando para eles a função-dever de interpretação das normas, incluindo tratados de direitos humanos positivados no ordenamento jurídico pátrio, para a melhor aplicação possível das mesmas, que se realizará através do controle de convencionalidade (MAZZUOLI, 2016).

Sobre os conflitos interculturais e a discussão entre universalismo e relativismo cultural nos direitos humanos, que influi no problema ora analisado, verifica-se que Flávia Piovesan faz uma elucidativa delimitação do tema a partir de vários autores classificando as correntes de pensamento mais atuais (PIOVESAN, 2016).

\section{A GLOBALIZAÇÃo COMO CAUSA DE AMPLIAÇÃO DOS CONFLITOS INTERCULTURAIS NOS DIREITOS HUMANOS INDÍGENAS: PRINCIPAIS ASPECTOS HISTÓRICOS E SOCIOLÓGICOS.}

Muito já se escreveu sobre o fenômeno da globalização e não se intenta aprofundar o tema nesse breve artigo. Aqui o importante é confirmar que a expansão do processo de globalização amplia os conflitos interculturais em geral e, consequentemente, os conflitos entre as culturas nativas e sua descendência e a cultura de outros povos, geralmente colonizadores, de origem europeia, asiática, africana, dependendo do contexto local.

\footnotetext{
${ }^{3}$ Nesse sentido: Pet. 3399/RR decisão do STF em 27.08.2008.
} 
Um enfoque interessante para o tema da globalização é o dado por Milton Santos (2008), no âmbito da Geografia científica, que pode ser utilizado neste artigo para ilustrar uma visão transdisciplinar do fenômeno.

Ao fim da II Guerra Mundial e da consolidação da Declaração de Direitos Humanos da Organização das Nações Unidas, surgiu no mundo capitalista mais desenvolvido o movimento chamado por Milton Santos de globalizante, como uma consequência da globalização (SANTOS, 2008). Para este estudioso, o modo de produção capitalista gerou a globalização que trouxe novas formas de totalitarismos, as quais ele coloca como resultados do que ele chama globalitarismo.

Na globalização os atores globais que se beneficiam do progresso técnico se esforçam em implantar um pensamento único, enquanto as percepções de mundo ficam cada vez mais fragmentadas nas massas empobrecidas materialmente e espiritualmente. O Estado, desta forma, torna-se incapaz de regular a vida coletiva, apesar dos esforços envidados (SANTOS, 2008).

Ainda segundo o autor, apesar das intenções hegemônicas dos atores da globalização, o capitalismo não tem total controle do mundo globalizado, por isso, se por um lado nele há perversidade, mas também está plantada a semente de uma mutação social, tecnológica e filosófica, substituindo o intuito de um pensamento único, para uma nova consciência universal, que segundo o autor está nascendo na Ásia, África e América Latina, em organizações não governamentais e nos movimentos sociais internacionalizados pelo progresso das comunicações (SANTOS, 2008).

Sobre essa consciência universal proposta por Milton Santos para substituir o pensamento único da elite de atores globais no mundo capitalista, entende-se ser possível um universalismo intercultural e comunitarista.

Tomando emprestada essa concepção da Geografia, percebe-se que no embate entre as concepções universalista e a relativista no campo dos direitos humanos, a solução aqui exposta é a adoção de um universalismo aberto a interculturalidade ao invés de um relativismo cultural exacerbado.

No mesmo sentido de uma proposta de universalismo aberto a interculturalidade, ensina Cançado Trindade (1994), citado por Flávia Piovesan (2016, p. 238), quando interpreta o § 5º da Declaração de Viena, adotada em 25 de maio de 1993, informando que finalmente se compreendeu a universalidade como constantemente enriquecida pela diversidade cultural, 
todavia ressaltando que não se pode alegar a diversidade cultural para se denegar ou violar direitos humanos.

Além da visão multicultural dos direitos humanos de Boaventura Santos que será aprofundada abaixo, outros autores seguem entendimentos semelhantes designando tipos de universalismo abertos ao diálogo intercultural, como o "universalismo de confluência” e o “universalismo pluralista” (PIOVESAN, 2016).

\subsection{AS VIOLAÇÕES DE DIREITOS HUMANOS DOS POVOS INDÍGENAS NA HISTÓRIA OCIDENTAL}

No âmbito do direito internacional a questão indígena conheceu dois momentos na sua evolução normativa e doutrinária: um primeiro momento onde o colonialismo condicionava a existência de quaisquer direitos indígenas às políticas assimilacionistas, e um segundo momento onde as políticas preservacionistas começaram a, gradativamente, adquirir força, inclusive normativa (CORDEIRO, 1999).

Durante o século XVI a discussão sobre a questão indígena no direito internacional era fortemente influenciada pelo interesse de legitimação do direito de descoberta e conquista. Tratava-se, inclusive, de definir a natureza e condição dos índios à luz de interesses políticos e econômicos da época. O direito de conquista, por exemplo, era frequentemente associado ao direito de fazer guerra justa aos infiéis que impedissem a propagação da fé cristã.

A oposição doutrinária a essa visão surgiria dentro da própria Igreja Católica e fez surgir na história defensores da causa indígena como Antônio de Montesinos, Bartolomé de Las Casas e Francisco de Vitória. Esses religiosos dominicanos reconheciam que os indígenas possuíam atributos humanos, como criaturas de Deus, capazes do uso da razão e de praticar a virtude. Tinham por isso o direito de viver em liberdade e manter os seus bens sem ser hostilizados ou escravizados.

Não se deve olvidar que a exploração e violações de direitos humanos indígenas não se limitava as Américas Portuguesa e Espanhola. A situação de exclusão de direitos não era diferente nas colônias anglo-saxãs e nos Estados Unidos após a independência. O “Naturalization Act” de 1790, por exemplo, dava direito apenas aos brancos adquirir cidadania norte-americana, após dois anos de residência naquele país, negando-se esse direito aos povos indígenas sobreviventes cujo os ancestrais lá residiram e tiveram domínio por milhares de anos 
(SANTOS JÚNIOR, 2016).

Noutro exemplo, Karl Marx, quando correspondente internacional de um veículo de comunicação norte-americano, chegou a noticiar prêmios em dinheiro que eram oferecidos pelos escalpos de indígenas homens, mulheres e crianças de Massachusetts Bay que foram considerados em rebeldia (SANTOS JÚNIOR, 2016).

Já Tocqueville, personagem histórico da independência norte-americana, afirmava que os indígenas ocupavam o território dos Estados Unidos, mas não o possuíam porquanto só a prática da agricultura lhes daria o direito de posse (SANTOS JÚNIOR,2016). Esse contexto associado à ganância por riquezas e terras explica boa parte dos conflitos entre os povos indígenas colonizados, brancos colonizadores, grupos econômicos e governos no processo histórico ora descrito.

Esses conflitos, no passado colonial, geraram legislações coloniais e até tratados internacionais entre a Coroa Portuguesa e outras nações colonizadoras e povos indígenas. Não vamos nos aprofundar na descrição dessa legislação e tratados, mas é importante demonstrar que, já na modernidade, com a persistência dos conflitos históricos e a expansão do Direito Internacional surgiu, no âmbito da OIT a Convenção no 107, de 05 de junho de 1957.

Segundo o sítio eletrônico da OIT a temática indígena já era debatida desde os anos 20 no âmbito da formação dessa organização internacional, visto que boa parte dos problemas relacionados com os trabalhadores, principalmente no Novo Mundo, diziam respeito ao emprego de trabalhadores indígenas.

Essa Convenção tinha uma natureza totalmente universalista sem adentrar em aspectos culturais de cada cultura indígena, mas já foi uma demonstração que a comunidade internacional se preocupava com as violações que esses trabalhadores sofriam. Após críticas dentro do âmbito da própria OIT e debates sobre a necessidade de uma abertura multicultural nas normas internacionais que protegiam os trabalhadores indígenas, surgiu a Convenção $n^{0}$ 169 da OIT, de 27 de junho de 1989.

A Convenção 169 da OIT foi assinada e ratificada pelos seguintes países até a presente data: Argentina, Bolívia, Brasil, Colômbia, Costa Rica, Chile, Dinamarca, Dominica, Equador, Espanha, Fiji, Guatemala, Holanda, Honduras, México, Nepal, Nicarágua, Noruega, Paraguai, Peru, República Centro Africana e Venezuela.

Verifica-se que países que não tem populações indigenas ou tribais (art. $1^{\text {o }}$, a e b, da referida Convenção) originárias em eu território, como a Dinamarca assinaram a convenção, 
porém há controvérsia se os povos ciganos etnicos poderiam ser considerados um povo tribal. Os ciganos etnicos possuem membros espalhados por quase todo o Mundo Ocidental.

Já outros países possuem povos tribais reconhecidos, como o povo lapão na Noruega, considerados tribais pelas organizações internacionais ONU e OIT.

O Brasil hoje possui 800 mil pessoas que se declaram índios. Menos que a argentina, onde 950 mil se consideram indígenas numa população quase 5 vezes menor, proporcionalmente ${ }^{4}$. Este número, contabilizado pelos órgãos oficiais de estatísticas, consideram a declaração pessoal do entrevistado. Essa declaração pessoal é importante e difere de números de órgãos como a FUNAI (voltados para os indígenas não assimilados), pois a Antropologia aceita a auto-identificação como início do processo de etnogênese de descendentes de indígenas e o consequente resgate da identidade cultural perdida.

Ao ratificar essa Convenção em julho de 2002, o Brasil, que além de Estado membro da OIT é um dos dez países com assento permanente no seu Conselho de Administração, aderiu ao instrumento de direito internacional mais abrangente para essa matéria, que procura garantir aos povos indígenas e tribais os direitos mínimos de salvaguardar suas culturas e identidade no contexto das sociedades que integram, se assim desejarem ${ }^{5}$.

A referida Convenção foi internalizada no Brasil através do Decreto $n^{0}$ 5.051, de 19 de abril de 2004. Nela está claramente definido quais são os povos considerados tribais ou indígenas no âmbito mundial.

A presente Convenção aplica-se a;

a) povos tribais em países independentes cujas condições sociais, culturais e econômicas os distingam de outros segmentos da comunidade nacional e cuja situação seja regida, total ou parcialmente, por seus próprios costumes ou tradições ou por uma legislação ou regulações especiais;

b) povos em países independentes considerados indígenas pelo fato de descenderem de populações que viviam no país ou região geográfica na qual o país estava inserido no momento da sua conquista ou colonização ou do estabelecimento de suas fronteiras atuais e que, independente de sua condição jurídica, mantêm algumas de suas próprias instituições sociais, econômicas, culturais e políticas ou todas elas.

Uma das inovações jurídicas da Convenção 169 foi a incorporação na norma dos conceitos antropológicos de etnogênese, reetnização e a própria definição de povo. Vejamos o

\footnotetext{
${ }^{4}$ Nesse sentido: ibge-brasil e idec-argentina (2010)

${ }^{5}$ Conferir: Convenção n 169 sobre povos indígenas e tribais e Resolução referente à ação da OIT / Organização Internacional do Trabalho. - Brasilia: OIT, 2011.
} 
que prescreve o art. $1^{\circ}$, 2 e 3 da referida Convenção.

2. A auto-identificação como indígena ou tribal deverá ser considerada um critério fundamental para a definição dos grupos aos quais se aplicam as disposições da presente Convenção (grifos nossos).

3. A utilização do termo povos na presente Convenção não deverá ser interpretada no sentido de acarretar qualquer implicação no que se refere a direitos que possam ser conferidos ao termo no âmbito do Direito Internacional.

Como se verifica acima, a Convenção 169 inovou trazendo uma maior abertura ao relativismo cultural sem perder sua base universalista. No caso permitindo critérios alheios a simples taxatividade das normas e buscando a integração com outras ciências, como a antropologia, para melhor identificar os sujeitos protegidos pela norma internacional.

\subsection{AS VIOLAÇÕES DE DIREITOS HUMANOS INDÍGENAS E SEUS ASPECTOS SOCIOLÓGICOS.}

Diante de tais problemas que colocam em lados opostos a Cultura e o Direito tradicional, que a sociedade brasileira e a internacional enfrentam hoje, identificamos como uma importante demanda filosófica e científica os estudos sobre o embate entre o universalismo e o relativismo dos direitos humanos, procurando a superação de qualquer eventual ideologia eurocêntrica que implique na exclusão das demais culturas.

Porém, sem esquecer os perigos do relativismo cultural como um extremo oposto de universalismo que, apesar das dificuldades, possui um propósito de garantia de direitos humanos básicos numa espécie de consenso universal do que é considerado fundamental para a dignidade humana. Esta é a proposta de Boaventura Santos para enfrentamento do problema conforme exposto por Sidney Guerra.

Com essas premissas de um dialogo intercultural de direitos humanos, Boaventura procura identificar o que chama de “concepção mestiça de direitos humanos”, isto é, a necessidade de fomentar o debate acerca da matéria levando em consideração os diversos sentidos locais, e não apenas um “falso universalismo” (GUERRA, 2014, p. 445-447).

Sobre a questão do universalismo em oposição ao relativismo nos direitos humanos Fernanda Bragato expõe que a Declaração Universal dos Direitos Humanos da ONU de dezembro de 1948 transcende, em nome do princípio da dignidade da pessoa humana, os propósitos limitados das Declarações clássicas (BRAGATO, 2010). 
E, embora atente que isso é um fato invisibilizado, o primeiro artigo da Declaração da ONU é reprodução fiel, não das declarações ocidentais modernas, mas da Declaração Americana dos Direitos e Deveres do Homem da OEA, de abril de 1948, que declara: “Todos os homens nascem livres e iguais em dignidade e direitos e, como são dotados pela natureza de razão e consciência, devem proceder fraternalmente uns para com os outros”.

O problema da construção universal dos direitos humanos talvez recaia, como lembra Sidney Guerra, no número limitado de Estados que firmou o texto da Declaração Universal dos Direitos Humanos de 1948. Um total de quarenta e oito estados votou a favor e oito estados se abstiveram. O número de Estados existentes no plano internacional era limitado, porquanto existia um número excesivo de colônias. Assim, a visão de mundo desses povos colonizados obviamente não foi contemplada em sua integralidade na Declaração (GUERRA, 2011).

O eurocentrismo é um tipo específico do gênero etnocentrismo. Segundo Amin Samin, uma forma particular de etnocentrismo se denomina eurocentrismo. Este conceito se refere à visão de mundo a partir da experiência européia ocidental, onde as vantagens e os benefícios para os europeus e seus descendentes, se tomam à custa de outras culturas, justificando esta ação com paradigmas ou normas éticas que proclaman benefícios universais para todos (SAMIN, 1989)

Nesse caminho, contextualizando o problema dentro da globalização, diversos autores, dentro e fora do campo jurídico, direta ou indiretamente, perceberam o surgimento dos conflitos interculturais entre o conceito universalista de direitos humanos e as concepções políticas e jurídicas de outras culturas, principalmente das culturas consideradas “exóticas”, muito destoantes da cultura do observador pertencente a cultura hegemônica, consideradas essas, do ponto de vista etnocêntrico, como culturas carentes da evolução propiciada pela modernidade. Daí resultando o conflito num problema típico da pós-modernidade.

Pretendem, autores como Fernanda Bragato e Boaventura Santos, desconstruir o entendimento dos direitos humanos na linha clássica das Declarações modernas de direitos. Tomamos como exemplo os estudos Fernada Bragato, que propõe uma ressignificação deste discurso:

Trata-se como ensina Lenio Streck, de um esforço hermeneutico no sentido de identificar e suspender os pré-juízos na busca da compreensão. Quem interpreta está exposto às confusões de seus próprios pré-conceitos, que podem levar a análises distorcidas, falsas compreensões e reprodução irrefletida do senso comum. (...) Essa postura hegemonica ocidental sugere que a história, os valores e as práticas de outras culturas não tiveram, e continuam não tendo, qualquer relevância para a construção 
dessa ideia, subestimando, especialmente, as importantes contribuições latinoamericanas para a edificação do potencial emancipatório da modernidade (BRAGATO, 2010, p. 106).

O exemplo mencionado acima da descisão judicial do Supremo Tribunal Federal sobre o caso da demarcação de terras indígenas na "Raposa Serra do Sol” mostra como conflitos interculturais e econômicos criam dilemas constititucionais entre duas visões opostas de dignidade, liberdade e igualdade. Se para o constitucionalismo moderno a liberdade permite algumas práticas não admitidas para outros povos, a dignidade e a igualdade também tem definições diferentes em cada cultura.

A partir do problema acima, verifica-se como uma solução para o dilema entre essa escolha entre duas visões opostas, qual seja a do universalismo ou a do reltivismo cultural, nos direitos humanos, a proposta da "hermenêutica diatópica” de Boaventura de Sousa Santos, pois, como será exposto adiante, as duas visões referidas se expõem às incompletudes de ambas as concepções (GUERRA, 2014).

Boaventura Sousa Santos (2010), afirma que os direitos humanos não são universais em sua aplicação, consensualmente existindo quatro sistemas de aplicação dos direitos humanos no plano internacional: o europeu, o interamericano, o africano e o asiático.

Parte da doutrina, baseando-se nos ensinamento de Boaventura, entende que os direitos humanos não podem ser universais ou transculturais porque o unico fato trascultural é a relatividade das culturas. A relatividade cultural (não o relativismo) exprime também a incompletude e a diversidade cultural (GUERRA, 2014).

Desta maneira, a questão específica sobre as condições da universalidade dos direitos humanos é uma questão cultural do ocidente. Logo, os direitos humanos são universais apenas quando olhados de uma perspectiva ocidental. Por isso, a própria questão da universalidade dos direitos humanos trai a pretensa universalidade do que quetiona ao questioná-la.

O argumento cultural de relativização à universalidade dos direitos humanos, somente podem ser aceitos como cláusula de salvaguarda àqueles que assim desejarem exercer o seu direito de escolha, mas nunca para coagir outros para se submeter a determinados comportamentos por se tratar de prática tradicional.

Daí a hermenêutica diatópica como uma solução de equilíbrio para os problemas interculturais, explica-se: essa é uma hermenêutica baseada na ideia que os topoi (do grego

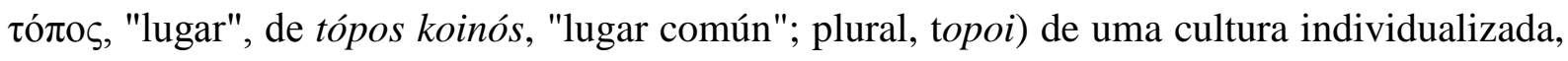
sem importar o quanto sejam fortes, são tão incompletos quanto qualquer cultura. A 
incompletude de uma cultura tida como universal deve ser calculada diante dos topoi da outra cultura colocada em conflito. O objetivo da hermenêutica diatópica não é alcançar a completude das culturas, algo aparentemente impossível, mas sim demonstrar a incompletude recíproca o quanto mais possível, de forma que se estabeleça um diálogo como se o observador ou estudioso tivesse um pé numa cultura e outro pé noutra. Daí seu caráter diatópico (SANTOS, 1997).

A tese, como se comentou acima, já possuiu aplicação prática na Justiça brasileira no voto do Ministro Carlos Ayres Britto no julgamento no Supremo Tribunal Federal da ação popular sobre a questão da demarcação contínua das terras indígenas “Raposa Serra do Sol” em Roraima (Pet. 3399/RR), podendo ter aplicação em questões hermenêuticas análogas, conforme se depreende do trecho a seguir da decisão em 27.08.2008:

\begin{abstract}
Situação que a nossa Lei Fundamental retratou como formadora de um indissociável laço entre cada etnia indígena e suas terras congenitamente possuídas; ou seja, possuídas como parte elementar da personalidade mesma do grupo e de cada um dos seus humanos componentes. O que termina por fazer desse tipo tradicional de posse fundiária um heterodoxo instituto de Direito Constitucional, e não uma ortodoxa figura de Direito Civil. Visto que terra indígena, no imaginário coletivo aborígine, deixa de ser um mero objeto de direito para ganhar a dimensão de verdadeiro ente ou ser que resume em si toda ancestralidade, toda coetaneidade e toda posteridade de uma etnia. É o que Boaventura de Sousa Santos chama de "hermenêutica diatópica", para dar conta do modo caracterizadamente cultural de interpretação dos direitos fundamentais. Metodologia interpretativa que, no caso dos indígenas, sedimentada na própria Constituição, nos orienta para fazer dos referidos "usos, costumes e tradições” o engate lógico para a definição da semântica da posse indígena, da semântica da permanência, da semântica da habitação, da semântica da produção, e assim avante (grifos nossos).
\end{abstract}

Pelo exposto, diante dos conflitos atuais entre a visão universalista e relativista dos direitos humanos (principalmente diante de direitos indígenas e tribais) e todos os problemas decorrentes para a efetividade desses direitos no sistema de proteção internacional dos direitos humanos, vislumbra-se a hermenêutica diatópica como instrumento de equilíbrio entre as duas correntes, visto como possível a construção de um universalismo multicultural.

Entendendo os direitos humanos como uma construção histórica, o método proposto por Boaventura Santos poderá iniciar uma nova construção rumo a uma visão ampla e abrangente. Quiçá uma visão de consenso. Tal construção seria um avanço na efetividade dos direitos humanos no âmbito do ordenamento jurídico interno e também no internacional de sua proteção.

Para Bustamante, a partir dos topoi, ainda que não se possa demonstrar apoditicamente a veracidade de uma tese qualquer, pelo menos é possível alcançar afirmações plausíveis, susceptíveis de serem resgatadas discursivamente. Esse processo, ao contrário do que um crítico 
positivista poderia imaginar, não é completamente livre, mas informado por deveres comunicativos (BUSTAMANTE, 2004).

Tais deveres (de afirmação, defesa, fundamentação, esclarecimento, repartição do ônus da prova, etc.) podem garantir suficientemente afirmações confiáveis, tornando cada vez maior o grau de justificação racional da conclusão obtida a partir da análise tópica (BUSTAMANTE, 2004).

Sinteticamente, a tópica que inspirou a hermenêutica diatópica recupera aperspectiva argumentativa, estabelecendo determinadas condições para o exercício da razão prática.

Bustamante, seguindo um conceito moderno de método, formulado por Fikentscher, que seria uma via de se alcançar um resultado concreto, entende ser possível ver a tópica como um método, de diretrizes antilegalistas, baseado na razão prática (BUSTAMANTE, 2004).

O autor acima entende que a grande virtude da tópica é introduzir na história do pensamento jurídico uma perspectiva argumentativa voltada para o caso concreto, rompendo com o ontologismo subjacente à jurisprudência e com o normativismo de Kelsen incapaz de atender a todos os reclamos do Direito (BUSTAMANTE, 2004).

\section{A CONVENÇÃO Na 169 DA OIT COMO MARCO DOS DIREITOS HUMANOS DOS POVOS INDÍGENAS NO ÂMBITO INTERNACIONAL}

A Convenção n 107 de 1957, até então considerada um marco histórico no processo de emancipação social dos povos indígenas, passou a ser criticada por suas tendências integracionistas e paternalistas, fato admitido pelo próprio Comitê de Peritos da OIT que, em 1986, considerou-a obsoleta e sua aplicação inconveniente no mundo moderno ${ }^{6}$.

A Convenção $n^{0} 107$ baseava-se exclusivamente em direitos individuais universais já previstos na Declaração Universal dos Direitos Humanos, sem considerar o necessário relativismo cultural ou interculturalidade na interpretação e aplicação das normas conforme cada realidade específica.

Abaixo, com dados do próprio site a OIT, elaborou-se uma tabela comparativa de quatro aspectos significativos das Convenções 107 e 169 da OIT em seus principais eixos normativos.

\footnotetext{
${ }^{6}$ Nesse sentido: Convenção n ${ }^{\circ} 169$ sobre povos indígenas e tribais e Resolução referente à ação da OIT / Organização Internacional do Trabalho. - Brasilia: OIT, 2011.
} 


\begin{tabular}{|l|l|}
\hline \multicolumn{1}{|c|}{ CONVENÇÃO 107 } & \multicolumn{1}{c|}{ CONVENÇÃO 109 } \\
\hline $\begin{array}{l}\text { Baseado no pensamento de que os povos } \\
\text { indígenas e tribais desapareceriam como } \\
\text { sociedades com “modernização”. }\end{array}$ & $\begin{array}{l}\text { Baseado na crença que os povos indígenas } \\
\text { são sociedades permanentes. }\end{array}$ \\
\hline $\begin{array}{l}\text { Faz referência a “populações indígenas e } \\
\text { tribais”. }\end{array}$ & $\begin{array}{l}\text { Faz referência a “povos indígenas e } \\
\text { tribais”. }\end{array}$ \\
\hline $\begin{array}{l}\text { Priorizava a integração dos índios na } \\
\text { comunidade. }\end{array}$ & $\begin{array}{l}\text { Reconhece e respeita a diversidade étnica } \\
\text { e cultural. }\end{array}$ \\
\hline $\begin{array}{l}\text { Só reconheceu os indígenas como sujeitos } \\
\text { de direitos individuais. }\end{array}$ & $\begin{array}{l}\text { Reconhece direitos de carácter individual } \\
\text { e coletivo. }\end{array}$ \\
\hline
\end{tabular}

Fonte: Elaboração própria

A Convenção 169 cuida com a importância devida da relação dos povos indígenas e tribais com a terra ou território que ocupam ou utilizam de alguma forma, principalmente aos aspectos coletivos dessa relação. Nesse contexto a Convenção reconhece o direito de posse e propriedade desses povos e estabelece medidas a serem tomadas para proteger esses direitos, inclusive sobre terras que, como observado em determinados casos, não sejam exclusivamente ocupadas por eles, mas às quais tenham, tradicionalmente, tido acesso para suas atividades e subsistência ${ }^{7}$.

Os povos nômades ou itinerantes são também objeto de atenção da Convenção, que, além de reconhecer seu direito aos recursos naturais das terras que ocupam, garante-lhes o direito de utilizá-los, administrá-los e conservá-los.

Ao ratificarem a Convenção, os Estados membros comprometem-se a adequar sua legislação e práticas nacionais a seus termos e disposições e a desenvolver ações com vistas à sua aplicação integral. Assumem também o compromisso de informar periodicamente a OIT sobre a aplicação da Convenção e de acolher observações e recomendações dos órgãos de supervisão da Organização.

Para Flávia Piovesan, foi nesse contexto de aceitação das suas diversidades e especificidades que, alguns anos depois em 2007, é aprovada a Declaração das Nações Unidas sobre o Direito dos Povos Indígenas (PIOVESAN, 2014).

Para a autora, essa Declaração enfatiza (mais que a Convenção 169) que "os povos indígenas têm o direito a preservar sua identidade cultural. ” Trata-se da primeira normatização

\footnotetext{
${ }^{7}$ Nesse sentido: Convenção n 169 sobre povos indígenas e tribais e Resolução referente à ação da OIT / Organização Internacional do Trabalho. - Brasilia: OIT, 2011.
} 
internacional sobre o tema no âmbito das Nações Unidas e trouxe em seu texto normas inovadoras, como o direito a praticar e revitalizar suas tradições e costumes; o direito a estabelecer sua própria mídia, dentre outras (PIOVESAN, 2014).

Assim como a Convenção 169, a Declaração também reconhece o direito às terras que ocupam, aludindo as diferentes relações materiais e espirituais que esses povos possuem com as suas terras e águas.

Por fim, a Declaração das Nações Unidas sobre o tema assegura aos povos independentes o direito à autodeterminação: a autonomia e o autogoverno e matérias relativas as questões locais, sem que isso interfira na soberania nacional de cada país.

Percebe-se que os direitos humanos indígenas no âmbito “onusiano” permitem a interpretação dessas normas a nível do Direito Internacional, bem como a nível da legislação de cada país, quando permitido algum grau de penetração dos direitos humanos na interpretação das normas constitucionais e infraconstitucionais, uma abertura ao relativismo cultural, desde que essa abertura esteja dentro do que está expresso na Declaração e sem conflitar com a Declaração Universal dos Direitos Humanos.

O grau de penetração dos direitos humanos internacionais no ordenamento de cada país dependerá, como ensina André de Carvalho Ramos, da efetividade que a Declaração Universal e declarações posteriores têm em cada país dentro do processo de internacionalização dos direitos humanos iniciado após a segunda guerra mundial (RAMOS, 2013). Assim, se a Justiça e a Lei Fundamental do país consideram a Declaração como uma norma não vinculante, ou seja, aquilo que se convenciona chamar de soft law, e apenas como referência para orientação futura da legislação interna, quando discricionariamente o Legislativo entender necessário, nesse caso, o grau de penetração será mínimo ou nulo.

A inexistência de um tratado internacional específico sobre proteção de direitos indígenas no âmbito das Nações Unidas reflete, para Flávia Piovesan, as dificuldades na conquista de um consenso entre os países quanto ao alcance dos direitos à terra e ao princípio da autodeterminação (PIOVESAN, 2014).

Os conflitos de terras e polêmicas sobre a possibilidade de certa autonomia para as comunidades indígenas não resultam num vasto material doutrinário sobre o tema, principalmente no Brasil. Com décadas de inúmeros conflitos violentos em razão de direitos de posse e propriedade, somente recentemente a Comissão Interamericana de Direitos Humanos da OEA admitiu um caso com essa temática originado no Brasil: o caso no 12.728 do povo 
indígena Xucuru e seus membros versus República Federativa do Brasil. E como anteriormente mencionado esse caso já recebeu uma sentença por parte do Tribunal Interamericano.

Com a ascensão da maior efetividade, pelo menos no âmbito das decisões do STF, como vimos acima, de direitos humanos indígenas, espera-se que a realidade acima se transforme dentro dos princípios já consagrados pela Convenção 169 da OIT e da Declaração das Nações Unidas de Direitos dos Povos Indígenas.

\section{A TRANSFORMAÇÃO SIGNIFICANTE DOS DIREITOS HUMANOS: PACHA MAMA, TEKO PORÃ E SUMAK KAWSAY}

Desde os anos 1980 a América Latina tem vivido uma onda de reformas constitucionais. O Brasil elaborou uma nova Constituição em 1988, a Colômbia em 1991, a Venezuela em 1999, o Equador em 2008 e a Bolívia em 2009. Já a Argentina revisou sua Constituição em 1994, e o México fez o mesmo em 2011 (GARGARELLA, 2014).

Dessas Constituições acima, a Constituição do Equador de 2008 tornou-se um marco no constitucionalismo mundial. Ela eleva esse país como um Estado constitucional genuíno e incorpora avanços de direitos impensáveis em textos constitucionais clássicos ocidentais, além de outras inovações, tais como a proibição da discriminação dos portadores de HIV ou ter o direito à cidade (com ciclovias), à água ou à alimentação (DALMAU; SILVA JÚNIOR, 2014).

\footnotetext{
Os direitos sociais giram em torno do "buen vivir", sumak kawsay, a incorporação do pensamento indígena referindo-se a condições de vida digna em relação ao mundo que nos rodeia. Portanto, o sumak kawsay vem acompanhado dos conhecidos direitos da natureza, um giro parabólico na compreensão das partes dogmáticas das Constituições: os ecossistemas, as florestas, as montanhas, as neves e os animais tornamse sujeitos de direitos. Uma Constituição que deve ser relida e sobre a qual, há muito o que refletir, não só porque representa um marco forjado pelo povo equatoriano, mas também porque aponta questões que a humanidade é capaz de avançar (DALMAU; SILVA JÚNIOR, 2014, p. 22).
}

Para os autores acima, a Constituição boliviana de 2009 é a mais complexa daquelas originadas nessa leva de processos constituintes. Uma Constituição que nasceu, nesse caso, diretamente a partir das reivindicações de povos indígenas.

No caso da Bolívia os povos indígenas constituem uma maioria que, segundo os autores, deixou de ser silenciosa e subordinada para constituir-se em "verdadeiro pilar da reconstrução democrática do Estado”.

Um Estado que já não seria mais a velha república colonial, mas que cria no horizonte 
a plurinacionalidade ("nações e povos indígenas originários campesinos", diz a Constituição em um metaconceito que desafia as regras gramaticais tradicionais). Sem os traumas atribuídos à velha Europa, que muitas vezes, observemos a Espanha - é relutante em reconhecer a plurinacionalidade e a compreender que a diversidade na unidade é uma qualidade, e não um problema, os bolivianos foram mais longe e recriaram um Estado, encarando suas questões frente a frente, reconhecendo em pé de igualdade as suas línguas, suas culturas, seus direitos (DALMAU; SILVA JÚNIOR, 2014, p. 23).

Verifica-se, analisando sob o prisma jurídico e esquecendo o debate ideológico partidário, ou ainda eventuais equívocos do Governo, uma plena compatibilidade principiológica com as Declarações das Nações Unidas de Direitos dos Povos Indígenas, A nova Constituição da Bolívia incorporou muitos dos princípios consagrados na Convenção 169 da OIT e Declarações das Nações Unidas de Direitos de Povos Indígenas, não porque houvesse essa finalidade.

Não há esse registro nos autores pesquisados, mas porque as motivações, as reivindicações, as razões e críticas a filosofia integracionista eram semelhantes no cenário local. Não diferiam muito das reivindicações levadas em consideração para a construção das normas internacionais referidas, conforme se deduz do exposto acima.

A Constituição da Bolívia trata-se de uma Carta de Direitos plural, que traz a baila inovações instigantes, como um Tribunal Constitucional eleito democraticamente pelo povo uma inovação defendida por Kelsen, mas que existem poucos exemplos.

Eleva-se a categoria de princípio, comparável ou conteúdo da dignidade humana, o denominado “vivir bien” (Sumaq qamaña), sendo seu conjunto normativo um verdadeiro escudo protetor da soberania popular: como em outros casos no Mundo democrático, qualquer mudança feita na Constituição boliviana de 2009, deverá passar por referendo popular.

Disposição que inevitavelmente lembra a todos a atual polêmica do processo constituinte venezuelano, não autorizado por referendo em voto universal e totalmente conflitante com a legítima Constituição daquele pais, aprovada por referendo, considerada democrática e avançada, como foi citada acima.

Não obstante a ameaça à democracia constatada acima, as novas Constituições latinoamericanas mostram também que os processos constituintes não são panaceias capazes de curar todos os males, porém ajudam a estabelecer as bases para transformar as condições de vida do povo gradativamente.

Um povo dirigido por uma Constituição democrática, dependerá menos do Governo para seu progresso. Uma Carta Fundamental emancipadora em torno a processos constituintes 
democráticos são o ideal perseguido desde a Revolução Francesa e outras revoluções transformadoras. É parte do espírito a natureza humana o desejo de segurança, estabilidade e proteção.

\section{CONSIDERAÇÕES FINAIS}

No presente artigo tenta-se explicar os conflitos interculturais entre os direitos humanos indígenas e os interesses de indivíduos, Estado e grupos econômicos dominantes, em seu contexto jurídico, histórico e sociológico, demonstrando as possibilidades de enfrentamento das questões levantadas através da interpretação hermenêutica da Convenção 169 da OIT e da Declaração das Nações Unidas de Direitos dos Povos Indígenas e Tribais, a exemplo do que fez, ainda que timidamente, a decisão do Supremo Tribunal Federal no caso da demarcação de terras indígenas “Raposa Serra do Sol”.

Todavia não se propõe uma interpretação livre, mas sempre fiel a um método que possua delimitações principiológicas claras dentro da Constituição, dos tratados de direitos humanos e declarações da ONU sobre o tema que deverão ser consideradas vinculantes.

Estrutura-se o problema e a proposta da hermenêutica diatópica de Boaventura Santos como uma solução possível para os conflitos interculturais, dentro de uma abordagem transdisciplinar necessária, pois as normas constitucionais, as normas internacionais de direitos humanos e direitos fundamentais inseridos no sistema constitucional, precisam ser originadas dos Estados e suas Constituições respaldadas pela soberania popular e essa envolve uma complexidade que só pode ser compreendida dentro de um estudo transdisciplinar que considere outras disciplinas.

Por conseguinte, verifica-se no artigo que a análise de conteúdos axiológicos humanistas presentes nas outras culturas e o diálogo de consenso entre os representantes das distintas culturas torna o direito internacional e o interno o menos excludentes possíveis. A exclusão manifestada nos conflitos interculturais que pode ser fator de criação de desigualdades, também pode ser fator de busca de consenso e construção de novas normas.

A visão de diferentes autores como Flávia Piovesan e Fernanda Bragato, a primeira com uma ótica universalista e a segunda com uma ótica relativista foi proposital para demonstrar que a necessidade de consenso, um pilar do direito moderno, foi e ainda é importante na reconstrução e construção dos direitos humanos. 
Descreve-se neste artigo as diferenças e avanços da Convenção $\mathrm{n}^{\mathrm{a}} 107$ para a Convenção $n^{\circ} 169$ da OIT, com o surgimento posterior da Declaração das Nações Unidas sobre Direitos dos Povos Indígenas, muito pertinentes a casos concretos verificados no nosso pais e no Mundo.

Demonstra-se também que se trata de um processo mundial com reflexos no constitucionalismo da América Latina, originado em conflitos sociais e reivindicações que remontam o colonialismo e a exploração e extermínio desses povos. Daí a natural ressignificação de direitos incorporando-se novos conceitos de direitos trazidos pela cosmovisão de outras culturas. Culturas essas consideradas originárias em nas Américas.

Por fim, assinala-se os perigos do universalismo irrestrito e do relativismo cultural extremado, como também de se perder o espírito democrático dos processos constituintes latino-americanos. A democracia, a cidadania e soberania popular não comportam quaisquer intervenções do Estado que sejam colidentes com os princípios constitucionais democráticos vigentes, decorrentes dessa mesma cidadania e vontade soberana do povo. Isso é a verdadeira democracia.

As novas experiências constitucionais na América Latina, nos oferece possibilidades, que como visto acima, provocam avanços democráticos nos países que fizeram recentemente de uma nova Constituição, com o respaldo popular.

\section{REFERÊNCIAS}

BUSTAMENTE, Thomas da Rosa de. Tópica e argumentação jurídica. Revista de Informação legislativa. vol. 41. n. 163. p.153-165. jul./set. 2004.

CORDEIRO, Enio. Política Indigenista Brasileira e Promoção Internacional dos Direitos das Populações Indígenas. Brasília: Instituto Rio Branco; Fundação Alexandre Gusmão, 1999.

CALLEGARI, André Luís; STRECK, Lenio Luiz; ROCHA, Leonel Severo (Org.). Constituição, Sistemas Sociais e Hermenêutica: Anuário do Programa de Pós-Graduação em Direito da UNISINOS: Mestrado e Doutorado, $n^{\circ}$ 07. Porto Alegre: Livraria do Advogado Editora; São Leopoldo: UNISINOS, 2010.

GARGARELLA, Roberto. Constitucionalismo latino-americano: a necessidade prioritária de uma reforma política. In: DIEHL, Diego Augusto; RIBAS, Luiz Otávio (org.). Constituinte Exclusiva: um outro sistema político é possível. Editora Expressão Popular, São Paulo, 2014. 
DALMAU, Rubén Martinez; SILVA JÚNIOR, Gladstone Leonel. O novo constitucionalismo latino-americano e as possibilidades da Constituinte no Brasil. In DIEHL, Diego Augusto; RIBAS, Luiz Otávio (org.). Constituinte Exclusiva: um outro sistema político é possível. Editora Expressão Popular, São Paulo, 2014

GUERRA, Sidney. Direito internacional dos direitos humanos. São Paulo: Saraiva, 2011. Direitos Humanos. 2 ed. São Paulo: Saraiva, 2014.

MAZZUOLI, Valério de Oliveira. O Controle Jurisdicional da Convencionalidade das leis. 4 ed. Revista dos Tribunais. São Paulo. 2016.

NEVES, Marcelo. Transconstitucionalismo. Martins Fontes. São Paulo. 2009.

PIOVESAN, Flávia. Direitos humanos e o direito constitucional internacional. 16 ed. São Paulo: Saraiva, 2014.

PORTAL DA COMISSÃO INTERAMERICANA DE DIREITOS HUMANOS. Disponível em: <http://www.corteidh.or.cr/docs/tramite/pueblo_indigena_xucuru_y_sus_miembros.pdf $>$. Acesso em : 16 maio 2017.

RAMOS, André de Carvalho. Teoria Geral dos Direitos Humanos na Ordem Internacional. 3 Ed. São Paulo. Ed. Saraiva, 2013.

SANTOS, Boaventura de Sousa. A gramática do tempo: para uma nova cultura política. 3. ed. São Paulo: Cortez, 2010.

. Uma concepção multicultural de direitos humanos. Lua Nova, São Paulo, n. 39, p. 105-124, 1997. Disponível em:

$<$ http://www.scielo.br/scielo.php?script=sci_arttext\&pid=S0102-

64451997000100007\&lng=en\&nrm=iso>. Acesso em: 09 abr. 2018.

SANTOS, Milton. Por uma outra globalização: do pensamento único à consciência universal. $18^{\text {a }}$ Ed. São Paulo: Record, 2008.

SANTOS JÚNIOR, Rosivaldo Toscano dos. A Guerra ao Crime e os Crimes da Guerra: uma crítica descolonial às políticas beligerantes no sistema de justiça criminal brasileiro.

Florianópolis: Empório do Direito, 2016.

SAMIN, Amin. El eurocentrismo. Crítica de una ideología. Ed. Siglo XXI. México. 1989

VILANOVA, Lourival. As dimensões politicas do Supremo Tribunal Federal. In: MARINHO, Josaphat; ROSAS, Roberto (org.). Sesquicentenário do Supremo Tribunal Federal. Ed. UNB. Brasília. 1978. 